\title{
ARTICLE \\ Alflutinib (AST2818), primarily metabolized by CYP3A4, is a potent CYP3A4 inducer
}

\author{
Xiao-yun Liu ${ }^{1,2}$, Zi-tao Guo ${ }^{1}$, Zhen-dong Chen ${ }^{1,2}$, Yi-fan Zhang ${ }^{1}$, Jia-lan Zhou ${ }^{1}$, Yong Jiang ${ }^{3}$, Qian-yu Zhao ${ }^{3}$, Xing-xing Diao ${ }^{1,2}$ and \\ Da-fang Zhong ${ }^{1,2}$
}

\begin{abstract}
Alflutinib (AST2818) is a third-generation epidermal growth factor receptor (EGFR) inhibitor that inhibits both EGFR-sensitive mutations and T790M mutations. Previous study has shown that after multiple dosages, alflutinib exhibits nonlinear pharmacokinetics and displays a time- and dose-dependent increase in the apparent clearance, probably due to its self-induction of cytochrome P450 (CYP) enzyme. In this study, we investigated the CYP isozymes involved in the metabolism of alflutinib and evaluated the enzyme inhibition and induction potential of alflutinib and its metabolites. The data showed that alflutinib in human liver microsomes (HLMs) was metabolized mainly by CYP3A4, which could catalyze the formation of AST5902. Alflutinib did not inhibit CYP isozymes in HLMs but could induce CYP3A4 in human hepatocytes. Rifampin is a known strong CYP3A4 inducer and is recommended by the FDA as a positive control in the CYP3A4 induction assay. We found that the induction potential of alflutinib was comparable to that of rifampin. The $E_{\max }$ of CYP3A4 induction by alflutinib in three lots of human hepatocytes were 9.24-, 11.2-, and 10.4-fold, while the fold-induction of rifampin $(10 \mu \mathrm{M})$ were $7.22-$, 19.4- and 9.46-fold, respectively. The EC 50 of alflutinibinduced CYP3A4 mRNA expression was $0.25 \mu \mathrm{M}$, which was similar to that of rifampin. In addition, AST5902 exhibited much weak CYP3A4 induction potential compared to alflutinib. Given the plasma exposure of alflutinib and AST5902, both are likely to affect the pharmacokinetics of CYP3A4 substrates. Considering that alflutinib is a CYP3A4 substrate and a potent CYP3A4 inducer, drug-drug interactions are expected during alflutinib treatment.
\end{abstract}

Keywords: alflutinib; AST5902; CYP3A4; metabolism; enzyme induction; drug-drug interaction

Acta Pharmacologica Sinica (2020) 41:1366-1376; https://doi.org/10.1038/s41401-020-0389-3

\section{INTRODUCTION}

Lung cancer is the most commonly diagnosed cancer $11.6 \%$ of the total cases of cancer) and the leading cause of cancer death globally ( $18.4 \%$ of the overall cancer-related deaths) [1]. In China, the most common cause of cancer-related deaths is lung cancer (24.1\%) [2]. Approximately $80 \%-85 \%$ of lung cancer types are nonsmall cell lung cancer (NSCLC), and the most common subtypes of NSCLC are lung adenocarcinoma (LUAD) and lung squamous cell carcinoma (LUSC) [3-5]. Epidermal growth factor receptor (EGFR) and Kirsten-RAS (KRAS) gene mutations are more common in LUAD, while in LUSC, the more common mutations are cyclindependent kinase inhibitor $2 \mathrm{~A}(C D K N 2 A)$ and tumor suppressor protein p53 (TP53) [6]. EGFR is also known as HER or ErbB1, which contains HER2 (ErbB2), HER3 (ErbB3) and HER4 (ErbB4) in its family [7]. The clustering of mutations in the ATP-binding pocket of EGFR may lead to its constitutive, ligand-independent activation [8]. The gain-of-sensitivity mutations include exon 19 deletion (amino acid residues 747-750) and the L858R mutation (nucleotide substitutions on exon 21) [9]. Hence, targeted therapy for the management of NSCLC with EGFR mutations is of epoch-making significance.

First-generation EGFR tyrosine kinase inhibitors (TKIs), namely, erlotinib and gefitinib, exert better clinical effects than conventional cytotoxic therapy $[10,11]$. Second-generation panHER EGFR TKIs, such as afatinib and dacomitinib, are notably different from first-generation EGFR TKIs, which reversibly compete with ATP. Afatinib and dacomitinib can improve the median progression-free survival (PFS) of NSCLC with sensitive EGFR mutations compared to gefitinib and erlotinib [12-15]. Secondary or acquired resistance to first-generation EGFR TKIs has been extensively studied. For instance, a threonine-to-methionine substitution at position 790 (T790M) in exon 20 can increase ATP affinity in the ATP pocket [16]. Third-generation EGFR TKIs covalently bind to cysteine 797 and target both sensitizing and T790M-specific mutations while sparing wild-type EGFR $[17,18]$. Osimertinib, a third-generation EGFR inhibitor, not only exhibits efficacy that is superior to platinum-based therapy plus pemetrexed in NSCLC patients harboring the T790M mutation but also displays greater efficacy in EGFR mutation-positive advanced NSCLC patients compared to standard EGFR TKIs $[19,20]$. In addition, olmutinib has been launched in South Korea for the treatment of patients with locally advanced or metastatic EGFR T790M mutation-positive NSCLC [21].

Alflutinib, also known as AST2818, is a third-generation EGFR inhibitor. A phase III clinical trial (FLAG, NCT03787992) is being conducted in China to assess whether alflutinib can serve as the

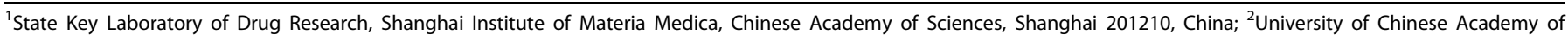
Sciences, Beijing 100049, China and ${ }^{3}$ Shanghai Allist Pharmaceuticals Inc., Shanghai 201203, China

Correspondence: Xing-xing Diao (xxdiao@simm.ac.cn) or Da-fang Zhong (dfzhong@simm.ac.cn)
}

Received: 2 November 2019 Revised: 19 February 2020 Accepted: 20 February 2020

Published online: 31 March 2020 
first-line treatment for locally advanced or metastatic NSCLC patients compared with gefitinib. Data from phase I/II clinical trials have demonstrated that alflutinib is generally well tolerated and exhibits significant clinical efficacy in NSCLC patients with the T790M mutation who progressed after EGFR-TKI therapy [22]. The $\mathrm{N}$-desmethyl metabolite AST5902 has been identified as the principal metabolite of alflutinib both in vitro and in vivo, which exerts remarkable antineoplastic activity similar to alflutinib (from a PK report in the phase I clinical study). Although alflutinib displays linear pharmacokinetics within the doses of 20-240 mg after single dose administration, its nonlinear pharmacokinetics and the accumulation of AST5902 have been observed after multiple dosing [23]. Alflutinib displays a time- and dosedependent increase in clearance (CL/F) following multiple doses, probably due to its self-induction through a cytochrome P450 (CYP) enzyme. Thus, the assessment of CYP enzymes involved in alflutinib biotransformation and the evaluation of CYP enzyme induction can help to understand the metabolism of alflutinib in vivo and further estimate potential drug-drug interactions (DDIs).

This study aimed to (i) elucidate the in vitro metabolism of alflutinib and its metabolites, (ii) identify the major metabolic enzymes involved in their metabolism, and (iii) evaluate the enzyme inhibition and induction potential of alflutinib and its metabolites. The findings would generate more reliable biotransformation information on alflutinib and provide evidence to support clinical DDI decision making.

\section{MATERIALS AND METHODS}

Materials

Alflutinib was provided by Shanghai Allist Pharmaceuticals Inc. (Shanghai, China). The following chemicals were purchased from Meilun Biotechnology Co., Ltd. (Dalian, China): 1aminobenzotriazole (ABT), 6a-hydroxy paclitaxel, a-naphthoflavone, acetaminophen- $\mathrm{d}_{4}$, chlormethiazole, ketoconazole, quercetin, quinidine, sulfaphenazole and ticlopidine. S-Mephenytoin and $6 \beta$-hydroxytestosterone were supplied by BD Gentest Corporation (Woburn, MA, USA). Phenacetin, tolbutamide, dextromethorphan, $O$-desmethyl dextromethorphan, 4'-hydroxymefentoin, paclitaxel and $1^{\prime}$-hydroxymidazolam were purchased from Sigma Chemical Co. Ltd. (St. Louis, MO, USA). Bupropion and hydroxy bupropion were supplied by Toronto Research Chemicals Inc. (Toronto, Canada). Testosterone was obtained from Sigma-Aldrich (St. Louis, MO, USA). 4'-Hydroxytolbutamide was provided by the Department of Microbiology, Shenyang Pharmaceutical University (Shenyang, China). Nicotinamide adenine dinucleotide phosphate (NADPH; reduced form) and midazolam were obtained from Roche Inc. (Mannheim, Germany). HPLC-grade ammonium acetate and formic acid were supplied by Roe Scientific Inc. (Neward, NJ, USA) and Tokyo Chemical Industry Co., Ltd. (Tokyo, Japan), respectively, while HPLC-grade acetonitrile and methanol were supplied by Merck KGaA (Darmstadt, Germany). Dimethyl sulfoxide (DMSO) was supplied by Sinopharm Chemical Reagent Co., Ltd. (Shanghai, China). A Milli-Q system was used to prepare deionized $\mathrm{H}_{2} \mathrm{O}$ (Molsheim, France). Recombinant human cytochrome P450 (CYP) isozymes (e.g., 1A2, 2A6, 2B6, 2C8, 2C9, 2C19, 2D6, 2E1, 3A4, and $3 \mathrm{~A} 5$ ) as well as pooled human liver microsomes (HLMs) were purchased from Corning Inc. (New York, NY, USA). Primary hepatocytes (lot \#DJJ, Caucasian male; 51 years of age; lot \#QBU, Caucasian male; 50 years of age; and lot \#HVN, Caucasian male; 33 years of age) were purchased from BiolVT (Baltimore, MD, USA).

Metabolism of alflutinib in HLMs

Before starting the experiments, the HLMs were thawed gently on ice. Then, $3 \mu \mathrm{M}$ alflutinib was added to the HLMs $(0.5 \mathrm{mg}$ protein $/ \mathrm{mL})$ in $100 \mathrm{mM}$ phosphate-buffered saline (PBS; pH 7.4) to a total volume of $100 \mu \mathrm{L}$. After incubating at $37^{\circ} \mathrm{C}$ for $3 \mathrm{~min}$, the reactions were initiated by the addition of $1.0 \mathrm{mM} \mathrm{NADPH}$. Following $1 \mathrm{~h}$ of incubation, the reactions were terminated by mixing with ice-cold acetonitrile at the same volume. All incubations were performed in duplicate and then analyzed by UPLC-UV/Q-TOF MS.

Incubation of HLMs with specific CYP inhibitors

HLMs were used to study the effects of CYP enzyme inhibitors on the metabolism of alflutinib. The incubation mixture $(100 \mu \mathrm{L})$ consisted of alflutinib $(3 \mu \mathrm{M}), \mathrm{HLMs}(0.5 \mathrm{mg}$ protein $/ \mathrm{mL}), \mathrm{NADPH}$ $(1 \mathrm{mM})$, PBS $(100 \mathrm{mM}, \mathrm{pH} 7.4)$ and a selective CYP inhibitor. The chemical inhibitors were as follows: a-naphthoflavone $(2 \mu \mathrm{M})$ for CYP1A/2 C, quercetin $(20 \mu \mathrm{M})$ for CYP2C8, sulfaphenazole $(6 \mu \mathrm{M})$ for CYP2C9, ticlopidine $(24 \mu \mathrm{M})$ for CYP2B6/2C19, quinidine $(8 \mu \mathrm{M})$ for CYP2D6, chlormethiazole $(24 \mu \mathrm{M})$ for CYP2E1, ketoconazole $(2 \mu \mathrm{M})$ for CYP3A and ABT $(1 \mathrm{mM})$ for all CYP enzymes. These inhibitors were preincubated with HLMs in the presence of $\mathrm{NADPH}$ for $10 \mathrm{~min}$ before adding the substrate. After that, the reactions were initiated by incubation at $37^{\circ} \mathrm{C}$ for $60 \mathrm{~min}$. Finally, the reactions were terminated by the addition of $100 \mu \mathrm{L}$ of icecold acetonitrile. All incubations were performed in duplicate, and the formation of metabolites was evaluated in the absence or presence of inhibitors.

The metabolism of alflutinib through recombinant human CYP isoenzyme

To identify the specific isoform that participates in the metabolism of alflutinib, $3 \mu \mathrm{M}$ alflutinib was mixed with recombinant human CYP1A2, 2A6, 2B6, 2C8, 2C9, 2C19, 2D6, 2E1, 3A4, or $3 \mathrm{~A} 5$ (25 pmol $\mathrm{P} 450 / \mathrm{mL}$ ) in a total volume of $100 \mu \mathrm{L}$. The reactions were initiated and terminated by the addition of $1 \mathrm{mM} \mathrm{NADPH}$ and $100 \mu \mathrm{L}$ of icecold acetonitrile, respectively. The incubation was carried at $37^{\circ} \mathrm{C}$ for $60 \mathrm{~min}$. All reactions were conducted in duplicate, followed by UPLC-UV/Q-TOF MS analysis.

\section{UPLC-UV/O-TOF MS detection}

The different metabolites of alflutinib were detected with an ACQUITY UPLC HSS T3 column $(1.8 \mu \mathrm{m}, 100 \mathrm{~mm} \times 2.1 \mathrm{~mm}$, Waters Corp., Milford, MA, USA) using a Waters ACQUITY UPLC system (Milford, MA, USA). The mobile phase contained a mixture of $5 \mathrm{mM}$ ammonium acetate with $0.05 \%$ formic acid (A) and acetonitrile (B). The gradient elution program was as follows: $5 \% \mathrm{~B}(1 \mathrm{~min}), 60 \% \mathrm{~B}$ (10 min), 95\% B (1 min and hold for $1 \mathrm{~min}$ ) and a 5\% B (1 min and hold for $2 \mathrm{~min}$ ) for column re-equilibration. The flow rate was set to $0.4 \mathrm{~mL} / \mathrm{min}$, and the column temperature was maintained at $40^{\circ} \mathrm{C}$. Eluted fractions were monitored by a UV detector at $280 \mathrm{~nm}$.

MS detection was carried out using a Waters SYNAPT G2 Q-TOF mass spectrometer (Milford, MA, USA) in positive ion electrospray ionization (ESI) mode. The desolvation gas flow and temperature were set to $800 \mathrm{~L} / \mathrm{h}$ and $450^{\circ} \mathrm{C}$, respectively. The cone gas flow was adjusted to $50 \mathrm{~L} / \mathrm{h}$, and the source temperature was maintained at $120^{\circ} \mathrm{C}$. The capillary voltage and cone voltage were maintained at $3.0 \mathrm{kV}$ and $40 \mathrm{~V}$, respectively. The SYNAPT G2 MS system was operated under resolution mode $(>20,000$ at full width half maximum). The rate of data acquisition was $0.3 \mathrm{~s} / \mathrm{scan}$, and all data were collected within 13 min under $\mathrm{MS}^{\mathrm{E}}$ acquisition mode. In the low-energy scan, the transfer CE and trap CE were $4 \mathrm{~V}$ and $6 \mathrm{~V}$, respectively. In the high-energy scan, the transfer CE was $20 \mathrm{~V}$, and the trap CE ramped from 20 to $25 \mathrm{~V}$. The MS was calibrated at $1 \mathrm{ppm}$ and operated through the leucine enkephalin Lockspray. MS data were acquired under continuum mode within a $\mathrm{m} / \mathrm{z}$ range of $50-1200$. MassLynx version 4.1 and UNIFI Portal software (Waters Corp., Milford, MA, USA) were employed for data processing.

Enzyme inhibition of alflutinib on major human CYP enzymes All CYP isoform-specific probes, such as phenacetin, bupropion, paclitaxel, tolbutamide, S-mephenytoin and dextromethorphan 
(for CYP1A2, 2B6, 2C8, 2C9, 2C19, and 2D6, respectively), as well as midazolam and testosterone (for CYP3A4), were dissolved in methanol. Alflutinib was dissolved in DMSO as a $100 \mathrm{mM}$ stock solution. The total volume was $100 \mu \mathrm{L}$, and the medium was 100 $\mathrm{mM}$ PBS containing mixed HLMs $(0.5 \mathrm{mg} / \mathrm{mL})$, probe substrates, NADPH $(1 \mathrm{mM})$ and different concentrations of alflutinib $(0,0.1$, $0.33,1,3.30,10,33.3$, and $100 \mu \mathrm{M})$. The reactions were preincubated at $37^{\circ} \mathrm{C}$ for $5 \mathrm{~min}$. Under the experimental conditions, the enzyme concentration and incubation time of the reaction system were all within a linear range (Supplementary Table S1).

Enzyme induction of alflutinib and AST5902 on the human CYP3A4 enzyme

For the assessment of enzyme induction, $7 \times 10^{5}$ hepatocytes $/ \mathrm{mL}$ were seeded into a collagen-coated 24 -well plate and placed in a $37^{\circ} \mathrm{C}$ humidified incubator with $5 \% \mathrm{CO}_{2}$ for $24 \mathrm{~h}$. The hepatocytes were treated with the human CYP3A4 enzyme inducer rifampin $(10 \mu \mathrm{M})$, alflutinib or AST5902 $(0.003,0.01,0.03,0.1,0.3,1,3$ or $5 \mu \mathrm{M}$ ) or $0.1 \%$ DMSO (control group) once daily for three consecutive days. After treatment, RNA extraction was performed with TRIzol (Invitrogen Life Technologies, Carlsbad, CA, USA) according to the manufacturer's protocol. cDNA synthesis was carried out using the PrimeScript RT reagent kit (Takara Bio Inc., Kusatsu, Japan). Real-time PCR was conducted on a StepOnePlus real-time PCR system (Applied Biosystems, Foster, CA, USA) using the SYBR green Premix Ex Taq kit (Takara Bio Inc., Kusatsu, Japan). The forward primer and reverse primer for CYP3A4 were $5^{\prime}$ ATCACTAGCACATCATTTGGAG-3' and 5'-GGAATGGAAAGGTTATTGAGAG-3', respectively. For GAPDH, the forward and reverse primers were 5'-AGAAGGCTGGGGCTCATTTG-3' and 5'-GAGGGGCCATCCACAGTCTTC-3', respectively. The levels of CDNA were quantitated by the comparative threshold cycle method using GAPDH as an internal standard. $E_{50}$ is the concentration of inducer at 50\% maximal effect of induction, which is obtained by a nonlinear regression test carried by GraphPad Prism version 5.0 (GraphPad Software Inc., San Diego, CA, USA).

\section{RESULTS}

UPLC/Q-TOF MS determination of alflutinib, AST5902 and AST28365

The chromatographic behaviors and MS fragmentation patterns of alflutinib and its metabolites AST5902 and AST28365 were first assessed to identify other potential alflutinib metabolites. Under the present chromatographic conditions, the retention time of alflutinib was found to be $9.37 \mathrm{~min}$. In $\mathrm{ESI}(+)$ mode, alflutinib generated a protonated molecular ion $[\mathrm{M}+\mathrm{H}]^{+}$at $\mathrm{m} / \mathrm{z}$ 569.261. Under higherenergy collision conditions, several fragment ions were observed at $m / z \quad 524.201 \quad\left(-\mathrm{C}_{2} \mathrm{H}_{7} \mathrm{~N}\right), \quad 441.192 \quad\left(-\mathrm{C}_{2} \mathrm{HF}_{3}-\mathrm{C}_{2} \mathrm{H}_{8} \mathrm{~N}\right), \quad 386.173$ $\left(-\mathrm{C}_{2} \mathrm{HF}_{3}-\mathrm{C}_{2} \mathrm{H}_{9} \mathrm{~N}-\mathrm{C}_{3} \mathrm{H}_{2} \mathrm{O}\right), \quad 370.172 \quad\left(-\mathrm{C}_{2} \mathrm{HOF}_{3}-\mathrm{C}_{2} \mathrm{H}_{9} \mathrm{~N}-\mathrm{C}_{3} \mathrm{H}_{2} \mathrm{O}\right)$, $302.102\left(-\mathrm{C}_{2} \mathrm{HF}_{3}-\mathrm{C}_{5} \mathrm{H}_{14} \mathrm{~N}_{2}-\mathrm{C}_{3} \mathrm{H}_{4} \mathrm{ON}-\mathrm{CH}\right), \quad 225.113\left(\mathrm{C}_{13} \mathrm{H}_{13} \mathrm{~N}_{4}{ }^{+}\right)$ and $72.077\left(\mathrm{C}_{4} \mathrm{H}_{10} \mathrm{~N}^{+}, 100 \%\right.$ abundance) for alflutinib (Fig. 1a). Based on the high-resolution mass spectral data, different tentative fragmentation patterns are illustrated in Fig. 1b. It was noted that the fragments of alflutinib were produced mainly by cleavage on the amine side chain, acrylamide and trifluoroethoxy moieties. In ESI $(+)$ mode, AST5902 eluted at $9.09 \mathrm{~min}$ and generated a protonated molecule $[\mathrm{M}+\mathrm{H}]^{+}$at $\mathrm{m} / \mathrm{z}$ 555.244. Under higher-energy collision conditions, several fragment ions were observed at $\mathrm{m} / \mathrm{z} 498.186$ $\left(-\mathrm{C}_{3} \mathrm{H}_{7} \mathrm{~N}, 100 \%\right.$ abundance $), 415.179\left(-\mathrm{C}_{2} \mathrm{HF}_{3}-\mathrm{C}_{3} \mathrm{H}_{8} \mathrm{~N}\right), 386.173$ $\left(-\mathrm{C}_{2} \mathrm{HF}_{3}-\mathrm{CH}_{7} \mathrm{~N}-\mathrm{C}_{3} \mathrm{H}_{2} \mathrm{O}\right), \quad 360.154 \quad\left(-\mathrm{C}_{2} \mathrm{HF}_{3}-\mathrm{C}_{3} \mathrm{H}_{9} \mathrm{~N}-\mathrm{C}_{3} \mathrm{H}_{2} \mathrm{O}\right)$, $344.164\left(-\mathrm{C}_{2} \mathrm{HOF}_{3}-\mathrm{C}_{3} \mathrm{H}_{9} \mathrm{~N}-\mathrm{C}_{3} \mathrm{H}_{2} \mathrm{O}\right), 302.102\left(-\mathrm{C}_{2} \mathrm{HF}_{3}-\mathrm{C}_{4} \mathrm{H}_{12} \mathrm{~N}_{2}-\right.$ $\left.\mathrm{C}_{3} \mathrm{H}_{4} \mathrm{ON}-\mathrm{CH}\right)$ and $225.110\left(\mathrm{C}_{13} \mathrm{H}_{13} \mathrm{~N}_{4}{ }^{+}\right)$for AST5902 (Fig. 2a). Compared to alflutinib, the fragmentation ion at $\mathrm{m} / \mathrm{z} 72.077$ was absent, and the tentative fragmentation profile is illustrated in Fig. 2b. It was noted that the fragments of AST5902 were produced mainly by cleavage on the amine side chain, acrylamide and trifluoroethoxy moieties. In addition, AST28365 eluted at $8.34 \mathrm{~min}$ and displayed a protonated molecular ion $[\mathrm{M}+\mathrm{H}]^{+}$at $m / z$ 555.242. Under higher-energy collision conditions, several fragment ions were observed at $\mathrm{m} / \mathrm{z} \quad 510.181 \quad\left(-\mathrm{C}_{2} \mathrm{H}_{7} \mathrm{~N}\right), \quad 427.177$ $\left(-\mathrm{C}_{2} \mathrm{HF}_{3}-\mathrm{C}_{2} \mathrm{H}_{8} \mathrm{~N}\right), \quad 372.156 \quad\left(-\mathrm{C}_{2} \mathrm{H}_{9} \mathrm{~N}-\mathrm{C}_{2} \mathrm{HF}_{3}-\mathrm{C}_{3} \mathrm{H}_{2} \mathrm{O}\right), \quad 356.162$ $\left(-\mathrm{C}_{2} \mathrm{H}_{9} \mathrm{~N}-\mathrm{C}_{2} \mathrm{HOF}_{3}-\mathrm{C}_{3} \mathrm{H}_{2} \mathrm{O}\right)$, $341.147\left(-\mathrm{C}_{2} \mathrm{H}_{9} \mathrm{~N}-\mathrm{C}_{2} \mathrm{HOF}_{3}-\mathrm{C}_{3} \mathrm{H}_{3} \mathrm{ON}\right)$, $288.089\left(-\mathrm{C}_{2} \mathrm{HF}_{3}-\mathrm{C}_{5} \mathrm{H}_{14} \mathrm{~N}_{2}-\mathrm{C}_{3} \mathrm{H}_{4} \mathrm{ON}-\mathrm{CH}\right), 211.094 \quad\left(\mathrm{C}_{12} \mathrm{H}_{11} \mathrm{~N}_{4}{ }^{+}\right)$ and $72.078\left(\mathrm{C}_{4} \mathrm{H}_{10} \mathrm{~N}^{+}, 100 \%\right.$ abundance) for AST28365 (Fig. 3a). The different tentative fragmentation patterns are illustrated in Fig. 3b. It was noted that the fragments of AST28365 were produced mainly by cleavage on the amine side chain, acrylamide and trifluoroethoxy moieties.

Metabolism of alflutinib in HLMs

In the presence of NADPH, 13 metabolites were identified from the HLMs treated with alflutinib (Fig. 4). Compared with the inactive HLMs, the predominant metabolite was AST5902, which showed a retention time of $9.09 \mathrm{~min}$. However, AST28365, which we predicted to be a major metabolite, was not detected in HLMs.

The data of the 13 detected metabolites, including the retention time, formula, observed and calculated $\mathrm{m} / \mathrm{z}$, MS area and fragment ions, are summarized in Table 1, and the structures of the 13 metabolites are illustrated in Fig. 5. The names of these metabolites were assigned according to their molecular weight, and the metabolites with similar molecular masses were sequentially named based on the order of retention time. The identities of the metabolites are displayed in the Supplementary Material.

The metabolism of alflutinib in recombinant human CYP isoenzymes

Alflutinib was hardly metabolized by some recombinant human CYP isoenzymes (e.g., 1A2, 2A6, 2B6, 2C8, 2C9, 2C19, 2D6, and $2 \mathrm{E} 1$ ), and only a few metabolites were produced during the metabolic process (Table 2 ). In contrast, alflutinib was extensively metabolized by CYP3A4. Specifically, the majority of phase I metabolites observed in HLMs were detected after 1-h exposure to CYP3A4, and at least $78 \%$ of alflutinib was transformed. Additionally, CYP3A5 was found to play a crucial role in the metabolism of alflutinib. Considering that CYP3A5 is less abundant than CYP3A4 in the liver, CYP3A4 has been regarded as the predominant enzyme involved in alflutinib metabolism. Similarly, the formation of AST5902 was catalyzed primarily by CYP3A4 but to a much lesser extent by CYP3A5. In addition, CYP2C8, CYP2C9, CYP2C19 and CYP2E1 could catalyze the formation of AST5902, although to a smaller extent. The relative contribution of the CYP450 subtypes to the metabolism of alflutinib and the formation of AST5902 was determined after normalization according to the relative amount of each CYP450 in human liver [24]. Based on the substrate (alflutinib) depletion method, alflutinib was found to be predominantly metabolized by CYP3A4 (78\%), and with regard to the metabolite (AST5902) formation method, the principal enzyme contributing to AST5902 formation was identified as CYP3A4 (79\%) (Supplementary Table S2).

Effects of CYP inhibitors on the formation of alflutinib metabolites in HLMs

The inhibitory effects of selective CYP inhibitors on the formation of alflutinib metabolites in HLMs were determined (Table 3). aNaphthoflavone (CYP1A2 inhibitor) and chlormethiazole (CYP2E1 inhibitor) exhibited no significant effects on the formation of alflutinib metabolites. Quercetin (CYP2C8 inhibitor) suppressed the production of AST5902 by $68 \%$ and inhibited the formation of M486, M497 and M584-1 to a certain degree. Sulfaphenazole (CYP2C9 inhibitor) suppressed the production of AST5902 by $45 \%$ and exhibited little effect on the formation of other metabolites. Ticlopidine (inhibitor of CYP2B6 and CYP2C19) suppressed the production of AST5902 by $38 \%$ and inhibited the formation of M539, M554-1 and M555 to some extent. Quinidine (CYP2D6 


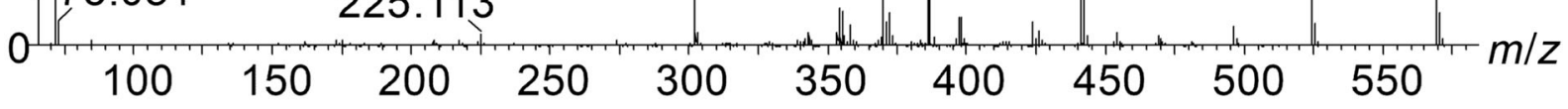

b<smiles>C=CC(=O)Nc1cc(Nc2nccc(-c3cn(C)c4ccccc34)n2)c(O)nc1N(C)C=C</smiles><smiles>C=CC(=O)Nc1cc(Nc2nccc(-c3cn(C)c4ccccc34)n2)c(OC(F)(F)F)nc1N(C)CC</smiles><smiles>C=CC(=O)Nc1cc(Nc2nccc(-c3cn(C)c4ccccc34)n2)c(OC(F)(F)F)nc1N(C)CC[NH+](C)C</smiles><smiles>C=CN(C)C</smiles>
m/z: 72.0808<smiles>Cn1cc(-c2ccccc2)c2cccnc21</smiles>

$m / z: 225.1135$<smiles>C=CN(C)c1nc(O)c(Nc2nccc(-c3cn(C)c4ccccc34)n2)cc1N</smiles>

$m / z: 386.1724$

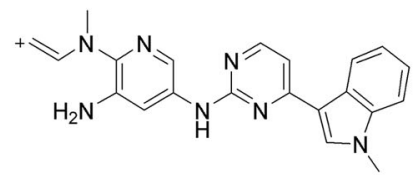

$m / z: 370.1775$<smiles>C1CCCC1</smiles><smiles>Oc1ncccc1Nc1nccc(-c2c[nH]c3ccccc23)n1</smiles>

m/z: 302.1036

Fig. 1 The MS fragmentation patterns of alflutinib. Mass spectra of alflutinib under high-collision energy in positive detection mode (a), and their tentative fragmentation profiles (b)

inhibitor) suppressed the production of AST5902 by $46 \%$ and inhibited the formation of M484 and M497 to some extent. Ketoconazole (CYP3A4/5 inhibitor) and ABT (inhibitor of all CYP isoenzymes) suppressed the production of AST5902 by $86 \%$ and $98 \%$, respectively. Except for M554-1, ketoconazole and ABT greatly suppressed the production of all the metabolites.

Altogether, the results of both CYP phenotyping assessments indicate that alflutinib is largely metabolized by the CYP3A4 enzyme.

Enzyme inhibition of alflutinib on major human CYP enzymes The residual activities of the 7 CYP isozymes (i.e., CYP1A2, 2B6, $2 \mathrm{C} 8,2 \mathrm{C} 9,2 \mathrm{C} 19,2 \mathrm{D} 6$, and $3 \mathrm{~A} 4)$ in HLMs were all $>50 \%$ at the maximum alflutinib concentration $(100 \mu \mathrm{M})$ in duplicate experiments (Table 4). Although $I_{50}$ values could not be determined, it was obvious that the values were more than $100 \mu \mathrm{M}$.

Enzyme induction of alflutinib on the human CYP3A4 enzyme The potential of alflutinib to induce CYP3A4 was assessed using primary human hepatocytes isolated from three lots (DJJ, QBU and HVN), and the results are presented in Table 5 . It was noted that the maximum responses (net maximum fold increase, $E_{\max }$ ) of alflutinib were 9.24-, 11.2- and 10.4-fold in DJJ, QBU and HVN, respectively. When DJ, QBU and HVN were treated with $10 \mu \mathrm{M}$ rifampin for $72 \mathrm{~h}$, the fold changes were 7.22--, 19.4-, and 9.46-fold, respectively. For DJJ and HVN, the mRNA expression level of 
a 100

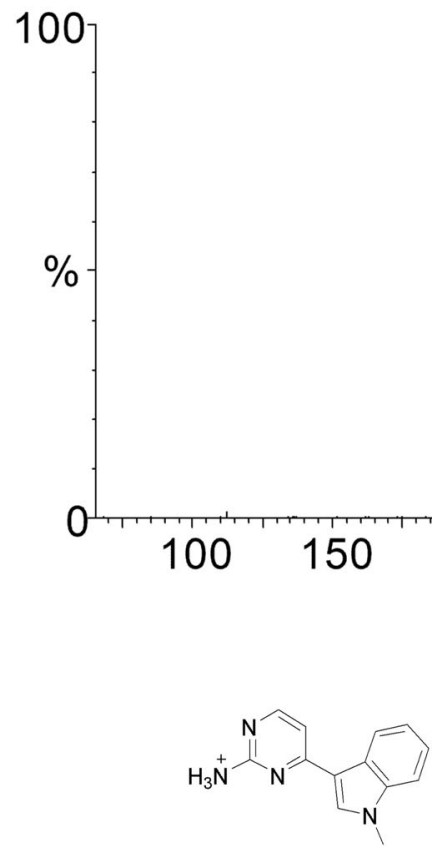<smiles>Oc1ncccc1Nc1cccc2[nH]ccc12</smiles>

m/z: 302.1036

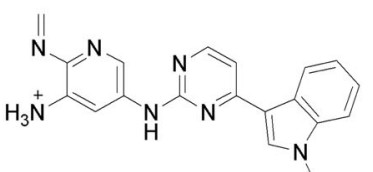

$m / z: 344.1618$ m/z: 225.1135<smiles>C=CC(=O)Nc1cc(Nc2nccc(-c3cn(C)c4ccccc34)n2)c(OCC(F)(F)F)nc1NC</smiles>

m/z: 498.1860<smiles>C=CC(=O)Nc1cc(Nc2nccc(-c3cn(C)c4ccccc34)n2)c(OCC(F)(F)F)nc1N(C)CCNC</smiles>

m/z: 555.2438<smiles>C=CC(=O)Nc1cc(Nc2nccc(-c3cn(C)c4ccccc34)n2)c(O)nc1NC</smiles>

$m / z: 415.1751$<smiles>C=CC(=O)Nc1cc(Nc2nccc(-c3cn(C)c4ccccc34)n2)cnc1N</smiles>

$m / z: 386.1724$

Fig. 2 The MS fragmentation patterns of AST5902. Mass spectra of AST5902 under high-collision energy in positive detection mode (a), and their tentative fragmentation profiles (b)

CYP3A4 increased with increasing alflutinib concentration in the range of $0.003-1 \mu \mathrm{M}$, while the mRNA expression level of CYP3A4 decreased when the alflutinib concentration was higher than $1 \mu \mathrm{M}$ (Supplementary Fig. S11). For QBU, the mRNA expression level of CYP3A4 increased with increasing alflutinib concentrations in the range of $0.003-5 \mu \mathrm{M}$ (Supplementary Fig. S11). As suggested by Fahmi and Ripp [25], when cell viability limits the acquisition of a full dose-response curve, the $E_{\max }$ can be regarded as the highest fold induction observed at a nontoxic concentration. To obtain the $\mathrm{EC}_{50}$, a nonlinear regression test was carried out by GraphPad Prism version 5.0 (GraphPad Software Inc., San Diego, CA, USA). $X$ represents the log of dose, $Y$ indicates the fold change, and least squares fit was used as the fitting method. After treating DJJ and HVN with alflutinib at 3 and $5 \mu \mathrm{M}$ for $72 \mathrm{~h}$, a significant cell morphological change was observed under the microscope, and cell survival decreased compared to the vehicle group. The dose-response curves of DJJ and HVN were bell-shaped, which could result from cytotoxicity or other factors [25]. Thus, the highest two concentrations were excluded from the nonlinear regression analysis [25]. However, the dose-response curve from $\mathrm{HVN}$ did not exhibit a sigmoidal curve, which overrated the $\mathrm{EC}_{50}$ value (Fig. 6). Therefore, the $\mathrm{EC}_{50}$ is presented as the concentration at $50 \%$ of the $E_{\text {max }}$.

According to the FDA guidelines (https://www.fda.gov/media/ 108130 /download), we calculated the value of $R_{3}$ (the AUC ratio of a victim drug with or without CYP inducer) using Eq. 1, where the value of $d$ is assumed to be 1 and the $E_{\max }$ is the maximal in vitro inductive effect. The $C_{\max }$ of alflutinib $(80 \mathrm{mg})$ was $108 \mathrm{nM}$ at steady state [22]. Given the low recovery of alflutinib in plasma at $37^{\circ} \mathrm{C}$ after $6 \mathrm{~h}$, plasma protein binding could not be determined 


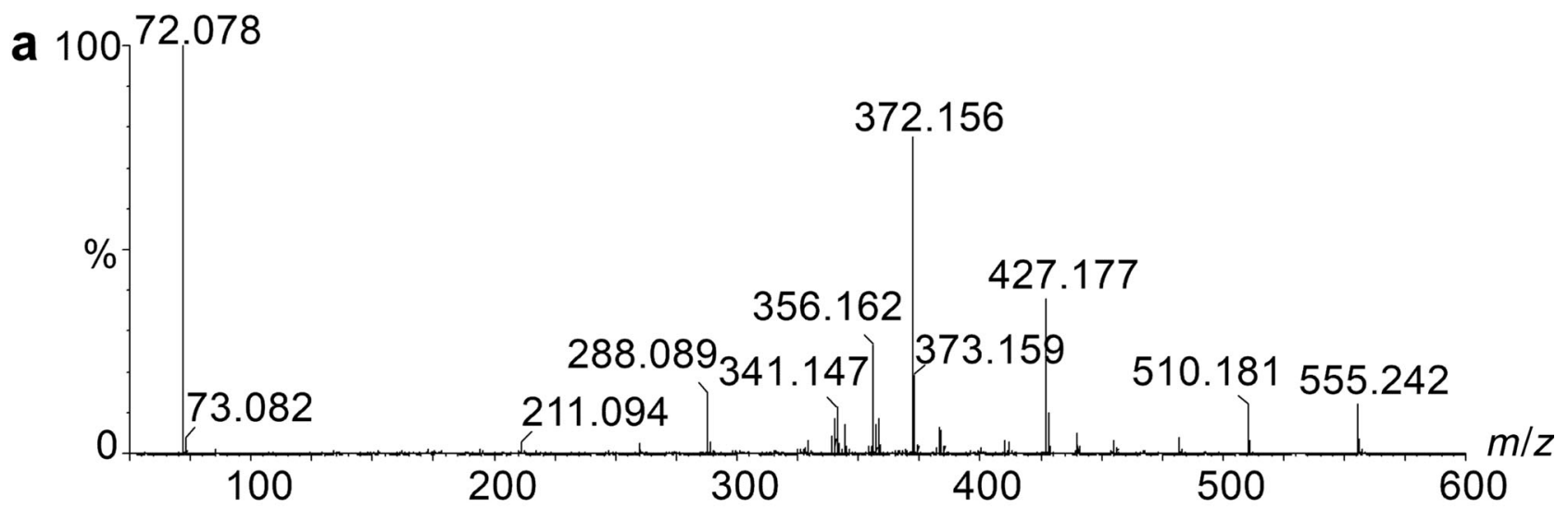

b<smiles></smiles><smiles>C=CC(=O)Nc1cc(Nc2nccc(-c3c[nH]c4ccccc34)n2)c(O)nc1N(C)C</smiles>

m/z: 427.1751

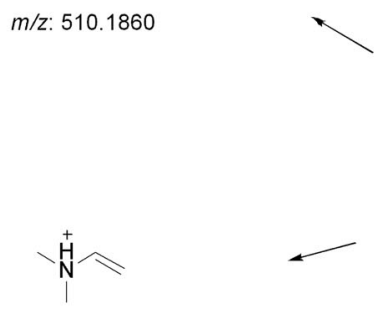<smiles>C=CC(=O)Nc1cc(Nc2nccc(-c3c[nH]c4ccccc34)n2)c(OCC(F)(F)F)nc1N(C)CCN(C)C</smiles>

m/z: 555.2438

m/z: 72.0808
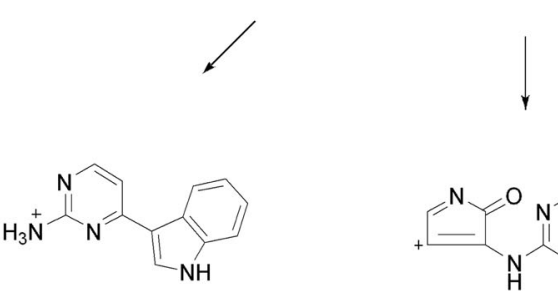

m/z: 211.0978



m/z: 288.0880

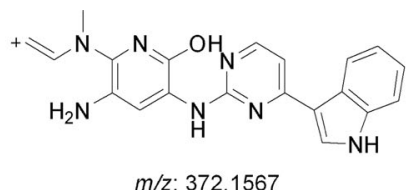

I

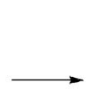

m/z: 356.1618

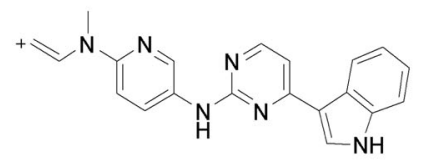

m/z: 341.1509

Fig. 3 The MS fragmentation patterns of AST28365. Mass spectra of AST28365 under high-collision energy in positive detection mode (a), and their tentative fragmentation profiles (b)

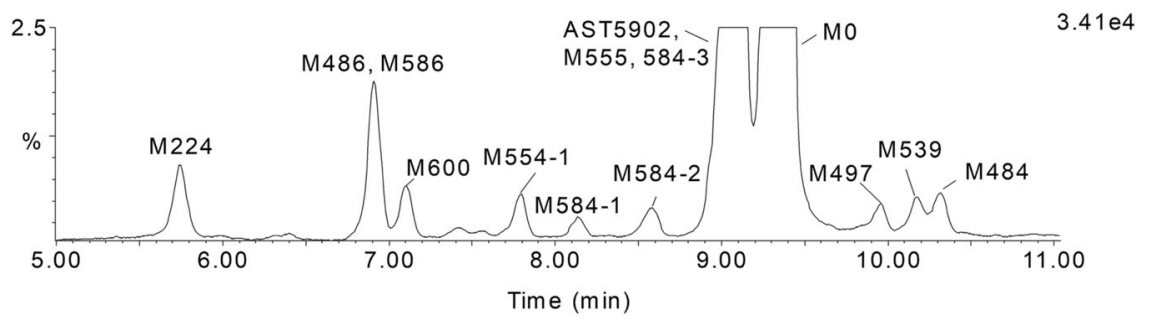

Fig. 4 Metabolic profiles of alflutinib in HLMs. The MS height of alflutinib was set as 100\%, and the MS height of AST5902 is approximate $50 \%$ of aflintinib. The relative MS height of other metabolite to alflutinib was shown 
Table 1. Characterization of alflutinib metabolites in HLMs through UPLC/Q-TOF MS

\begin{tabular}{|c|c|c|c|c|c|c|c|c|}
\hline Name & Metabolic pathway & $\begin{array}{l}\text { Retention } \\
\text { time (min) }\end{array}$ & Formula & $\begin{array}{l}\text { Observed } \\
(\mathrm{m} / \mathrm{z})\end{array}$ & $\begin{array}{l}\text { Calculated } \\
(\mathrm{m} / \mathrm{z})\end{array}$ & $\begin{array}{l}\text { Mass error } \\
(\mathrm{ppm})\end{array}$ & MS area & Fragment lons \\
\hline M224 & $N$-Dealkylation & 5.74 & $\mathrm{C}_{13} \mathrm{H}_{12} \mathrm{~N}_{4}$ & 225.1136 & 225.1135 & 0.6 & $2.32 \times 10^{3}$ & 208.082 \\
\hline M486 & O-Dealkylation & 6.90 & $\mathrm{C}_{26} \mathrm{H}_{30} \mathrm{~N}_{8} \mathrm{O}_{2}$ & 487.2567 & 487.2564 & 0.6 & $5.77 \times 10^{3}$ & $\begin{array}{l}442.198,387.183 \\
372.162,72.082\end{array}$ \\
\hline M586 & Dioxidation of AST5902 & 6.92 & $\mathrm{C}_{27} \mathrm{H}_{29} \mathrm{~F}_{3} \mathrm{~N}_{8} \mathrm{O}_{4}$ & 587.2332 & 587.2337 & -0.7 & $9.00 \times 10^{2}$ & $\begin{array}{l}530.172,512.165,413.160, \\
358.140,\end{array}$ \\
\hline M600 & Dioxidation & 7.11 & $\mathrm{C}_{28} \mathrm{H}_{31} \mathrm{~F}_{3} \mathrm{~N}_{8} \mathrm{O}_{4}$ & 601.249 & 601.2493 & -0.5 & $2.60 \times 10^{3}$ & $\begin{array}{l}556.199,473.184 \\
418.165,72.081\end{array}$ \\
\hline M554-1 & $N$-Demethylation & 7.78 & $\mathrm{C}_{27} \mathrm{H}_{29} \mathrm{~F}_{3} \mathrm{~N}_{8} \mathrm{O}_{2}$ & 555.244 & 555.2438 & 0.3 & $2.12 \times 10^{3}$ & $\begin{array}{l}510.181,427.168,372.156 \\
356.162,225.109,72.078\end{array}$ \\
\hline M584-1 & Oxidation & 8.14 & $\mathrm{C}_{28} \mathrm{H}_{31} \mathrm{~F}_{3} \mathrm{~N}_{8} \mathrm{O}_{3}$ & 585.254 & 585.2544 & -0.6 & $1.04 \times 10^{3}$ & $\begin{array}{l}541.208,386.173 \\
370.172,72.081\end{array}$ \\
\hline M584-2 & Oxidation & 8.59 & $\mathrm{C}_{28} \mathrm{H}_{31} \mathrm{~F}_{3} \mathrm{~N}_{8} \mathrm{O}_{3}$ & 585.2544 & 585.2544 & 0 & $1.83 \times 10^{3}$ & $457.188,386.173,72.081$ \\
\hline M555 & $\begin{array}{l}\text { Oxidation and acetylation } \\
\text { of M498 }\end{array}$ & 8.94 & $\mathrm{C}_{26} \mathrm{H}_{24} \mathrm{~F}_{3} \mathrm{~N}_{7} \mathrm{O}_{4}$ & 556.1913 & 556.1915 & -0.3 & $2.24 \times 10^{3}$ & $498.186,225.110$ \\
\hline AST5902 & $N$-Demethylation & 9.09 & $\mathrm{C}_{27} \mathrm{H}_{29} \mathrm{~F}_{3} \mathrm{~N}_{8} \mathrm{O}_{2}$ & 555.2442 & 555.2438 & 0.7 & $7.84 \times 10^{4}$ & $\begin{array}{l}498.186,415.179,386.173 \\
360.154,344.164,302.102 \\
225.110\end{array}$ \\
\hline M584-3 & Oxidation & 9.19 & $\mathrm{C}_{28} \mathrm{H}_{31} \mathrm{~F}_{3} \mathrm{~N}_{8} \mathrm{O}_{3}$ & 585.2544 & 585.2544 & 0 & $1.74 \times 10^{3}$ & $524.201,441.183$ \\
\hline Mo & Parent & 9.36 & $\mathrm{C}_{28} \mathrm{H}_{31} \mathrm{~F}_{3} \mathrm{~N}_{8} \mathrm{O}_{2}$ & 569.2604 & 569.2595 & 1.6 & $2.47 \times 10^{5}$ & $\begin{array}{l}524.201,441.192,386.173 \\
370.172,302.102, \\
225.113,72.077\end{array}$ \\
\hline M497 & N-Dealkylation & 9.94 & $\mathrm{C}_{24} \mathrm{H}_{22} \mathrm{~F}_{3} \mathrm{~N}_{7} \mathrm{O}_{2}$ & 498.1855 & 498.186 & -1 & $1.49 \times 10^{3}$ & $\begin{array}{l}415.176,360.159,344.160 \\
302.098,225.113\end{array}$ \\
\hline M539 & Acetylation of M497 & 10.16 & $\mathrm{C}_{26} \mathrm{H}_{24} \mathrm{~F}_{3} \mathrm{~N}_{7} \mathrm{O}_{3}$ & 540.1957 & 540.1965 & -1.6 & $1.82 \times 10^{3}$ & $398.169,225.113$ \\
\hline M484 & Dealkylation and oxidation & 10.3 & $\mathrm{C}_{23} \mathrm{H}_{19} \mathrm{~F}_{3} \mathrm{~N}_{6} \mathrm{O}_{3}$ & 485.1548 & 485.1543 & 0.9 & $2.42 \times 10^{3}$ & $467.142,347.123,225.113$ \\
\hline
\end{tabular}

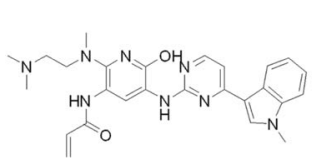

M486

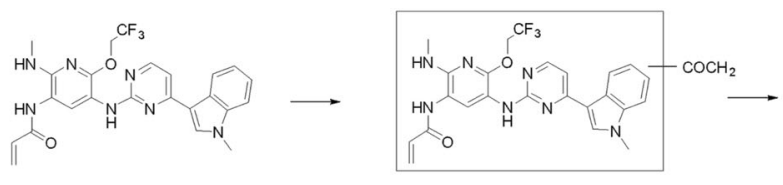

M539

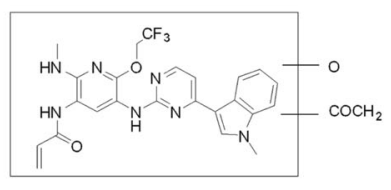

M555
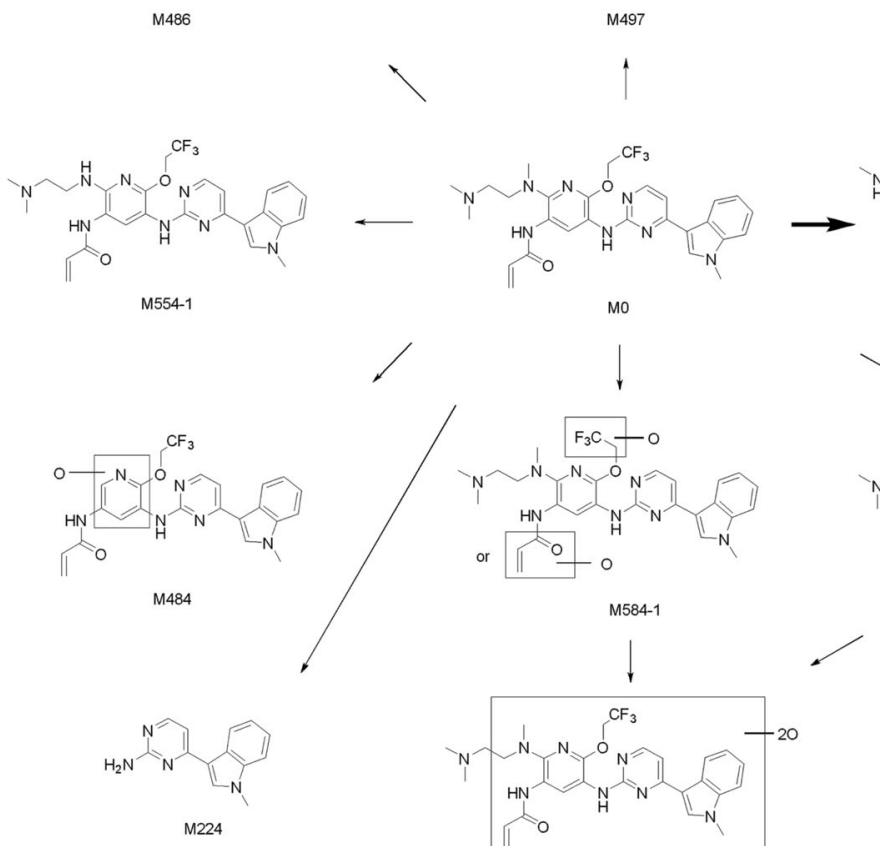

$\underset{n}{\longrightarrow}$
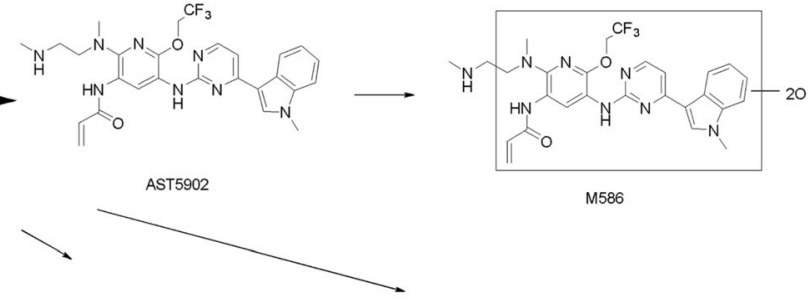

Mo

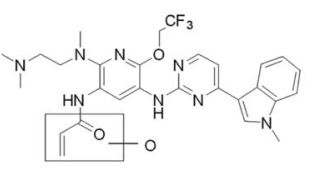

M584-2

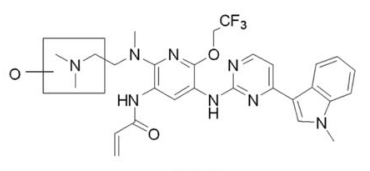

M584-1
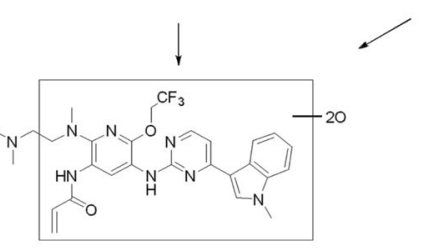

M600

Fig. 5 Proposed metabolic pathway of alflutinib in HLMs. The structure of 13 metabolites were showed. Except for M224, M486, M497, M554-1 and AST5902, the exact modified positions of other metabolites remained unclear 


\begin{tabular}{|c|c|c|c|c|c|c|c|c|c|c|c|c|}
\hline Name & Retention time (min) & Elemental composition & $1 \mathrm{~A} 2$ & $2 A 6$ & 2B6 & $2 \mathrm{C} 8$ & $2 C 9$ & $2 C 19$ & 2D6 & $2 \mathrm{E} 1$ & $3 \mathrm{~A} 4$ & $3 \mathrm{~A} 5$ \\
\hline Mo & 9.36 & $\mathrm{C}_{28} \mathrm{H}_{31} \mathrm{~F}_{3} \mathrm{~N}_{8} \mathrm{O}_{2}$ & 93.69 & 95.15 & 95.84 & 95.02 & 91.04 & 96.18 & 96.27 & 95.02 & 21.07 & 66.58 \\
\hline M224 & 5.74 & $\mathrm{C}_{13} \mathrm{H}_{12} \mathrm{~N}_{4}$ & - & - & 1.50 & 0.74 & 3.36 & 0.73 & 2.46 & 1.93 & 38.81 & 10.14 \\
\hline M484 & 10.3 & $\mathrm{C}_{23} \mathrm{H}_{19} \mathrm{~F}_{3} \mathrm{~N}_{6} \mathrm{O}_{3}$ & - & - & - & - & - & - & - & - & 2.38 & 0.61 \\
\hline M497 & 9.94 & $\mathrm{C}_{24} \mathrm{H}_{22} \mathrm{~F}_{3} \mathrm{~N}_{7} \mathrm{O}_{2}$ & - & - & - & - & - & - & - & - & 0.66 & - \\
\hline M554-1 & 7.78 & $\mathrm{C}_{27} \mathrm{H}_{29} \mathrm{~F}_{3} \mathrm{~N}_{8} \mathrm{O}_{2}$ & 0.35 & 0.68 & 0.48 & 0.35 & 0.60 & 0.28 & 0.22 & 0.52 & 0.81 & 0.57 \\
\hline AST5902 & 9.09 & $\mathrm{C}_{27} \mathrm{H}_{29} \mathrm{~F}_{3} \mathrm{~N}_{8} \mathrm{O}_{2}$ & - & - & - & 1.35 & 1.79 & 0.19 & - & 0.22 & 9.80 & 5.93 \\
\hline M555 & 8.94 & $\mathrm{C}_{26} \mathrm{H}_{24} \mathrm{~F}_{3} \mathrm{~N}_{7} \mathrm{O}_{4}$ & - & - & - & - & - & - & - & - & 0.74 & - \\
\hline M584-1 & 8.14 & $\mathrm{C}_{28} \mathrm{H}_{31} \mathrm{~F}_{3} \mathrm{~N}_{8} \mathrm{O}_{3}$ & 4.66 & - & - & 1.19 & 0.37 & 0.72 & - & - & 0.50 & 3.75 \\
\hline M584-2 & 8.59 & $\mathrm{C}_{28} \mathrm{H}_{31} \mathrm{~F}_{3} \mathrm{~N}_{8} \mathrm{O}_{3}$ & - & - & - & - & - & - & - & - & 1.26 & 2.44 \\
\hline
\end{tabular}

Table 3. Effects of the selective inhibitors on the formation of metabolites during HLMs incubations

\begin{tabular}{lllllllllll}
\hline Name & MS area & \multicolumn{1}{l}{ Relative MS area (\%) } \\
\cline { 3 - 12 } & HLM & ANF & QUE & SPZ & TCL & QD & KET & CMT & ABT \\
& Control & 1 A2 & 2C8 & 2C9 & 2B6/ & 2D6 & 3A & 2E1 & CYP \\
& & & & & 2 C19 & & & & \\
\hline M0 & $2.47 \times 10^{5}$ & 89 & 92 & 58 & 61 & 94 & 227 & 87 & 165 \\
M224 & $2.32 \times 10^{3}$ & 127 & 70 & 88 & 94 & 80 & 36 & 100 & 26 \\
M484 & $2.42 \times 10^{3}$ & 101 & 62 & 89 & 84 & 39 & - & 136 & - \\
M486 & $5.77 \times 10^{3}$ & 147 & 31 & 92 & 86 & 113 & 18 & 131 & 19 \\
M497 & $1.49 \times 10^{3}$ & 81 & 37 & 62 & 62 & 40 & - & 89 & - \\
M539 & $1.82 \times 10^{3}$ & 67 & 57 & 62 & 55 & 58 & - & 81 & - \\
M554-1 & $2.12 \times 10^{3}$ & 96 & 53 & 58 & 58 & 100 & 109 & 83 & 76 \\
AST5902 & $7.84 \times 10^{4}$ & 97 & 32 & 55 & 62 & 54 & 14 & 88 & 2 \\
M555 & $2.24 \times 10^{3}$ & 74 & 51 & 65 & 44 & 64 & 0 & 73 & - \\
M584-1 & $1.04 \times 10^{3}$ & 112 & 38 & 65 & 143 & 121 & 59 & 115 & - \\
M584-2 & $1.83 \times 10^{3}$ & 126 & 76 & 85 & 77 & 161 & - & 96 & 31 \\
M584-3 & $1.74 \times 10^{3}$ & 80 & 82 & 99 & 75 & 66 & 32 & 122 & 32 \\
M586 & $9.00 \times 10^{2}$ & 117 & 64 & 91 & 111 & 88 & - & 111 & - \\
M600 & $2.60 \times 10^{3}$ & 95 & 85 & 85 & 104 & 93 & 13 & 102 & 12 \\
\hline
\end{tabular}

in vitro by using the equilibrium dialysis method. The unbound fraction of alflutinib in human plasma $\left(f_{u, p}\right)$ was estimated to be $7.484 \%$ by ADMET Predictor9.5 (Simulation Plus). The values of $R_{3}$ for DJJ, QBU and HVN were calculated to be $0.31,0.26$ and 0.28 , respectively. All these values were below the cutoff value of 0.8 , indicating that the induction potential of alflutinib should be further investigated by mechanistic models or clinical DDI assessment using sensitive index substrates:

$R_{3}=1 /\left[1+\left(d \times E_{\max } \times 10 \times I_{\max , \mathrm{u}}\right) /\left(\mathrm{EC}_{50}+\left(10 \times I_{\max , \mathrm{u}}\right)\right)\right]$.

Enzyme induction of AST5902 on the human CYP3A4 enzyme Considering that the steady-state plasma exposure of AST5902 is comparable to that of alflutinib at a high dose, we evaluated the potential induction of CYP3A4 by AST5902. The results are shown in Table 5 and Supplementary Fig. S12. At lower concentrations (0.003-0.03 $\mu \mathrm{M})$, AST5902 could inhibit the mRNA transcription of CYP3A4. With increasing concentration, AST5902 exhibited an induction effect. The maximum induction values for DJJ, QBU and HVN were 1.79-, 4.71- and 3.42-fold, respectively.

After treating DJJ with AST5902 at 3 and $5 \mu \mathrm{M}$ for $72 \mathrm{~h}$, a significant cell morphological change was observed under the microscope, and cell survival decreased compared to the vehicle group. A similar phenomenon was observed when QBU and HVN were treated with AST5902 at $5 \mu \mathrm{M}$ for $72 \mathrm{~h}$. For the $\mathrm{EC}_{50}$ values, the two highest concentrations were excluded for DJJ, while only the highest concentration was excluded for QUE and HVN. Similar to alflutinib, the dose-response curve of AST5902 in HVN did not exhibit a sigmoidal curve. Thus, the $\mathrm{EC}_{50}$ of AST5902 in HVN was the concentration of AST5902 at $50 \% E_{\max }$ (Fig. 7). The $C_{\text {max }}$ of AST5902 (80 mg) was $72.5 \mathrm{nM}$ at steady state [22], and the $f_{u, p}$ of AST5902 was estimated to be $7.482 \%$ by ADMET Predictor. The values of $R_{3}$ for DJJ, QBU, and HVN were $0.78,0.42$, and 0.80 , respectively. These results indicate that AST5902 is also likely to cause DDIs when coadministered with a CYP3A4 substrate.

Enzyme induction of rifampin on the human CYP3A4 enzyme Rifampin is a potent CYP3A4 inducer, which remains one of the best choices for clinical DDI studies of CYP3A4 induction. The $\mathrm{EC}_{50}$ of rifampin for CYP3A4 induction in human hepatocytes ranged from 0.1 to $0.33 \mu \mathrm{M}$ [26-28]. The in vivo concentrations of rifampin were $10-18 \mu \mathrm{M}$, and the $f_{u, p}$ of rifampin was $0.175[27,29]$. To calculate the $R_{3}$ value of rifampin, we set the $E C_{50}$ and unbound plasma concentration to $0.25 \mu \mathrm{M}$ and $2.5 \mu \mathrm{M}$, respectively. It was found that the $R_{3}$ values of rifampin were $0.12,0.05$ and 0.10 in DJJ, QBU and HVN, respectively, which are consistent with the findings of clinical trials.

\section{DISCUSSION}

Our study revealed that alflutinib was predominantly metabolized by CYP3A4 (78\%), and CYP3A4 (79\%) was the major enzyme that catalyzes alflutinib to form AST5902. As a substrate of CYP3A4, it is important to assess the effects of CYP3A4 inhibitors or inducers on alflutinib metabolism and pharmacokinetics. Osimertinib, an alflutinib analog, is primarily metabolized by CYP3A4 [30]. Rifampin (a potent CYP3A4 inducer) exerts a moderate effect (2- to 5-fold) on the clinical pharmacokinetics of osimertinib, while itraconazole (a potent CYP3A4 inhibitor) has no remarkable clinical 
Table 4. Inhibition of CYP activities in HLMs

\begin{tabular}{|c|c|c|c|c|c|c|c|c|c|}
\hline \multirow[t]{3}{*}{ CYP isozymes } & \multirow[t]{3}{*}{ Probe drug alone } & \multicolumn{8}{|c|}{ Percentage of residual metabolic activity (\%) } \\
\hline & & \multicolumn{8}{|c|}{ Alflutinib concentration $(\mu \mathrm{M})$} \\
\hline & & 0 & 0.1 & 0.33 & 1 & 3.33 & 10 & 33.3 & 100 \\
\hline CYP1A2 & Phenacetin O-deethylation & 100 & 70.4 & 74.1 & 91.2 & 75.3 & 73.3 & 78.3 & 67.2 \\
\hline CYP2B6 & Bupropion hydroxylation & 100 & 97.8 & 97.5 & 95.2 & 102 & 101 & 95.8 & 88.8 \\
\hline CYP2C8 & Paclitaxel $6 \alpha$-hydroxylation & 100 & 103 & 105 & 101 & 102 & 95.3 & 82 & 84.3 \\
\hline CYP2D6 & Dextromethorphan O-demethylation & 100 & 100 & 96.4 & 102 & 105 & 112 & 107 & 107 \\
\hline CYP3A4 & Midazolam 1'-hydroxylation & 100 & 79.6 & 77.6 & 77.7 & 78.4 & 78 & 66 & 62.5 \\
\hline CYP3A4 & Testosterone $6 \beta$-hydroxylation & 100 & 100 & 102 & 101 & 112 & 91.3 & 82.8 & 57.9 \\
\hline
\end{tabular}

Table 5. Induction of CYP3A4 mRNA expression in human hepatocytes

\begin{tabular}{|c|c|c|c|c|c|c|c|c|c|c|}
\hline Test compound & Concentration $(\mu \mathrm{M})$ & \multicolumn{3}{|c|}{ Maximum fold induction } & \multicolumn{3}{|c|}{$\mathrm{EC}_{50}(\mu \mathrm{M})$} & \multicolumn{3}{|l|}{$R_{3}$} \\
\hline Alflutinib & $0.003-5$ & 9.24 & 11.2 & 10.4 & 0.25 & 0.24 & 0.25 & 0.31 & 0.26 & 0.28 \\
\hline AST5902 & $0.003-5$ & 1.79 & 4.71 & 3.42 & 0.29 & 0.13 & 0.68 & 0.78 & 0.42 & 0.80 \\
\hline Rifampin & 10 & 7.22 & 19.4 & 9.46 & & $0.1-0.33$ & & 0.12 & 0.05 & 0.10 \\
\hline
\end{tabular}

DJJ

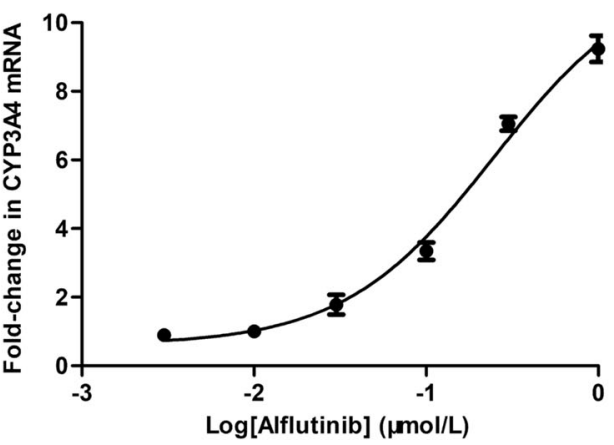

HVN

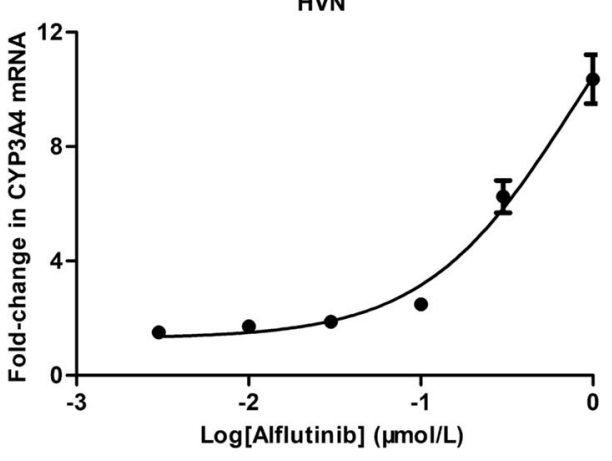

QBU

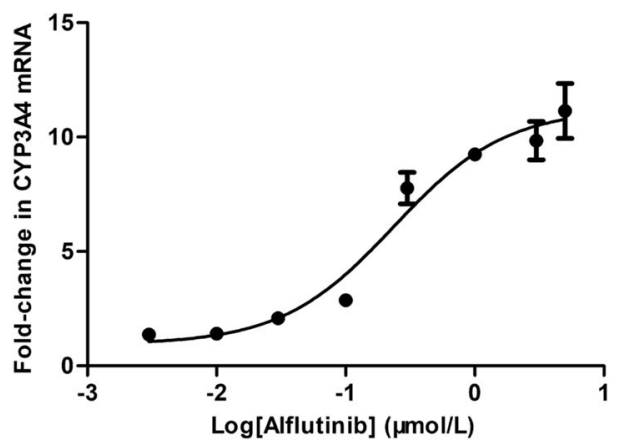

arithmetic mean \pm standard deviation $(n=3)$

effect on the metabolism of osimertinib $(<1.25$-fold) [31]. The findings of the current phenotyping experiments confirm that alflutinib is a substrate of CYP3A4. In view of the structural similarity between alflutinib and osimertinib, it is most likely that alflutinib may undergo DDIs when coadministered with CYP3A4 inducers. However, additional investigation is needed to explore the clinical DDIs of alflutinib with CYP3A inducers and inhibitors. The results of this study demonstrated that alflutinib did not 
DJJ



HVN

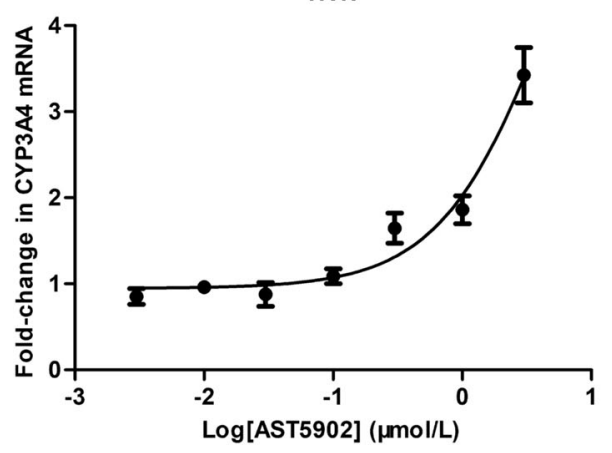

QBU

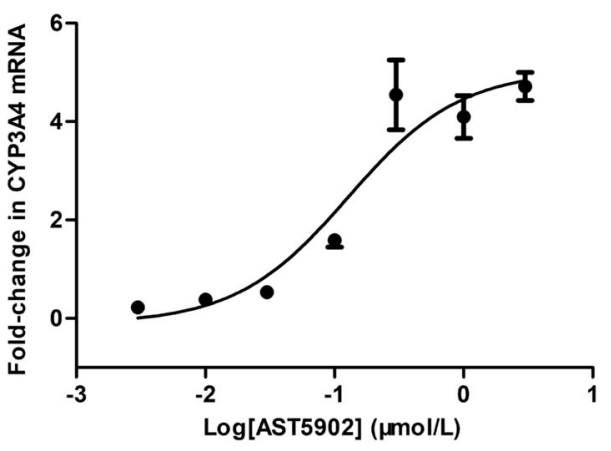

Fig. 7 Dose-response curves for the mRNA expression levels of CYP3A4 induced by AST5902 in DJJ, QBU and HVN. Data are presented as arithmetic mean \pm standard deviation $(n=3)$

inhibit P450 in vitro; however, it could be a potent CYP3A4 inducer. We also investigated the potential of alflutinib to act as an inducer of CYP1A2 and CYP2B6, and the study endpoint was enzyme activity levels using a probe substrate. Alflutinib produced a change in CYP1A2 and CYP2B6 enzyme activity that was less than the cutoff value of $40 \%$ of the positive control (Supplementary Table S3 and S4). Thus, alflutinib did not induce CYP1A2 and CYP2B6 in vitro. We did not investigate whether alflutinib is a CYP2C inducer, which is a limitation of our study.

Alflutinib is the first new drug that exhibits strong CYP3A4 enzyme induction and will undergo a clinical DDI study in China. Induction of drug-metabolizing enzymes is not as common as inhibition, and CYP3A4 induction is not generally considered a concern for safety. However, CYP3A4 induction can lead to subtherapeutic drugs and/or increase the formation of active or reactive metabolites [26]. In human hepatocytes, $1 \mu \mathrm{M}$ alflutinib could exhibit a higher $E_{\max }$ value for CYP3A4 induction compared to $10 \mu \mathrm{M}$ rifampin in DJJ and HVN. Rifampin has been recognized as a potent CYP3A inducer, but alflutinib exhibited similar or even greater $E_{\text {max }}$. This indicates that alflutinib can serve as a novel CYP3A inducer. The maximum concentration of alflutinib was set to $5 \mu \mathrm{M}$, which exhibited toxic effects on DJJ and HVN but might be insufficient for QBU to achieve $E_{\max }$. Alflutinib exerts strong induction potential for CYP3A4, and the $C_{\max }$ of alflutinib at therapeutic doses is likely to induce CYP3A4 in vivo. However, alflutinib is less likely to have a profound effect on the CYP3A4 substrate, similar to rifampin, because of its dosage. Therefore, it is necessary to conduct a clinical trial to assess the CYP3A4 induction potential of alflutinib. Considering the high exposure of AST5902 and the structures of alflutinib and AST5902, we also evaluated the CYP3A4 induction potential of AST5902. At low concentrations, AST5902 inhibited the mRNA transcription of CYP3A4, but the underlying mechanisms remain unclear.
Compared to alflutinib and rifampin, the in vitro induction effects of AST5902 were found to be less significant. However, given the plasma exposure of AST5902, AST5902 is also likely to cause a clinical DDI with CYP3A4-sensitive substrates.

Upon incubation of $3 \mu \mathrm{M}$ alflutinib with human hepatocytes at $37^{\circ} \mathrm{C}$ for $3 \mathrm{~h}$, the primary metabolite was identified as AST5902, accounting for $52 \%$ of the remaining alflutinib concentration. Other metabolites accounted for less than 1.2\% of alflutinib (unpublished data). In addition, AST5902 exerted CYP3A4 induction potential, which might contribute to the induction effect of alflutinib.

In phase $\mathrm{I} / \mathrm{II}$ clinical trials, the $C_{\max }$ and AUC of a single-dose alflutinib were elevated in a dose-dependent manner among NSCLC patients in the dose range of $20-240 \mathrm{mg}$ [23]. After multiple doses, the increase in alflutinib exposure was less than that of a single dose. The AUC of AST5902 greatly increased, even exceeding that of alflutinib in the $240 \mathrm{mg}$ dosage group. In addition, alflutinib showed a time-dependent and dosedependent increase in clearance (CL/F) following multiple doses. CYP phenotyping studies and CYP enzyme induction indicated that alflutinib was a substrate and inducer of CYP3A4. Thus, the self-induction of alflutinib may be the reason for the phenomenon observed in clinical trials. Given the exposure of human alflutinib at an $80 \mathrm{mg}$ dose, alflutinib is speculated to activate clinical pharmacokinetic DDIs when coadministered with CYP3A4-sensitive substrates, including midazolam and triazolam. Considering that the activation of pregnane $X$ receptor (PXR) can induce CYP3A and CYP2C, further evaluation of the potential of alflutinib to induce $C Y P 2 C$ should be conducted [32].

In conclusion, alflutinib is a substrate and potent inducer of CYP3A4 but not an inhibitor of CYP450 enzymes. Thus, clinically relevant pharmacokinetic DDIs are likely to take place when 
alflutinib serves as a victim coadministered with CYP inducers or inhibitors or acts as a perpetrator coadministered with CYP3A4sensitive substrates. Alflutinib is the first drug developed in China that exhibits potent CYP3A4 induction, and related clinical trials will be conducted in the future. Nevertheless, it is necessary to evaluate the effects of self-induction on the efficacy of alflutinib.

\section{ACKNOWLEDGEMENTS}

This work was supported by the Strategic Priority Research Program of the Chinese Academy of Sciences [XDA12050306] and the National Natural Science Foundation of China [81521005, 81903701].

\section{AUTHOR CONTRIBUTIONS}

$X Y L, D F Z, Y J$, and QYZ participated in the research design; XYL, ZTG, ZDC, and JLZ conducted the experiments; $X Y L$ and YFZ performed data analysis; XYL, DFZ, and XXD wrote or contributed to the writing of the manuscript.

\section{ADDITIONAL INFORMATION}

The online version of this article (https://doi.org/10.1038/s41401-020-0389-3) contains supplementary material, which is available to authorized users.

Competing interests: The authors declare no competing interests.

\section{REFERENCES}

1. Bray F, Ferlay J, Soerjomataram I, Siegel RL, Torre LA, Jemal A. Global cancer statistics 2018: globocan estimates of incidence and mortality worldwide for 36 cancers in 185 countries. CA Cancer J Clin. 2018;68:394-424.

2. Feng RM, Zong YN, Cao SM, Xu RH. Current cancer situation in China: good or bad news from the 2018 global cancer statistics? Cancer Commun. 2019;39:22.

3. Sun S, Schiller JH, Spinola M, Minna JD. New molecularly targeted therapies for lung cancer. J Clin Invest. 2007;117:2740-50.

4. Alvarez M, Roman E, Santos ES. New targets for non-small-cell lung cancer therapy. Expert Rev Anticanc. 2007;7:1423-37.

5. Molina JR, Yang P, Cassivi SD, Schild SE, Adjei AA. Non-small cell lung cancer: epidemiology, risk Factors, treatment, and survivorship. Mayo Clin Proc. 2008;83:584-94.

6. Herbst RS, Morgensztern D, Boshoff $C$. The biology and management of nonsmall cell lung cancer. Nature. 2018;553:446-54.

7. Yarden Y, Sliwkowski MX. Untangling the ErbB signalling network. Nat Rev Mol Cell Biol. 2001;2:127-37.

8. Lynch TJ, Bell DW, Sordella R, Gurubhagavatula S, Okimoto RA, Brannigan BW, et al. Activating mutations in the epidermal growth factor receptor underlying responsiveness of non-small-cell lung cancer to gefitinib. N Engl J Med. 2004;350:2129-39.

9. Sharma SV, Bell DW, Settleman J, Haber DA. Epidermal growth factor receptor mutations in lung cancer. Nat Rev Cancer. 2007;7:169-81.

10. Fukuoka $M, W u$ YL, Thongprasert S, Sunpaweravong $P$, Leong SS, Sriuranpong V, et al. Biomarker analyses and final overall survival results from a phase III, randomized, open-label, first-line study of gefitinib versus carboplatin/paclitaxel in clinically selected patients with advanced non-small-cell lung cancer in Asia (IPASS). J Clin Oncol. 2011;29:2866-74.

11. Zhou $C, W u ~ Y L$, Chen G, Feng J, Liu XQ, Wang $C$, et al. Erlotinib versus chemotherapy as first-line treatment for patients with advanced EGFR mutationpositive non-small-cell lung cancer (OPTIMAL, CTONG-0802): a multicentre, openlabel, randomised, phase 3 study. Lancet Oncol. 2011;12:735-42.
12. Paz-Ares L, Tan EH, O'Byrne K, Zhang L, Hirsh V, Boyer M, et al. Afatinib versus gefitinib in patients with EGFR mutation-positive advanced non-small-cell lung cancer: overall survival data from the phase Ilb LUX-Lung 7 trial. Ann Oncol. 2017;28:270-7.

13. Kim Y, Lee SH, Ahn JS, Ahn MJ, Park K, Sun JM. Efficacy and safety of afatinib for EGFR-mutant non-small cell lung cancer, compared with gefitinib or erlotinib. Cancer Res Treat. 2019;51:502-9.

14. Wu YL, Cheng Y, Zhou X, Lee $K H$, Nakagawa K, Niho S, et al. Dacomitinib versus gefitinib as first-line treatment for patients with EGFR-mutation-positive nonsmall-cell lung cancer (ARCHER 1050): a randomised, open-label, phase 3 trial. Lancet Oncol. 2017;18:1454-66.

15. Ramalingam SS, O'Byrne K, Boyer M, Mok T, Janne PA, Zhang H, et al. Dacomitinib versus erlotinib in patients with EGFR-mutated advanced nonsmall-cell lung cancer (NSCLC): pooled subset analyses from two randomized trials. Ann Oncol. 2016;27:423-9.

16. Pao W, Miller VA, Politi KA, Riely GJ, Somwar R, Zakowski MF, et al. Acquired resistance of lung adenocarcinomas to gefitinib or erlotinib is associated with a second mutation in the EGFR kinase domain. Plos Med. 2005;2:225-35.

17. Han W, Du Y. Recent development of the second and third generation irreversible epidermal growth factor receptor inhibitors. Chem Biodivers. 2017;14: e1600372.

18. Cheng $\mathrm{H}$, Nair SK, Murray BW. Recent progress on third generation covalent EGFR inhibitors. Bioorg Med Chem Lett. 2016;26:1861-8.

19. Mok TS, Wu YL, Ahn MJ, Garassino MC, Kim HR, Ramalingam SS, et al. Osimertinib or platinum-pemetrexed in EGFR T790M-positive lung cancer. N Engl J Med. 2017:376:629-40.

20. Soria JC, Ohe Y, Vansteenkiste J, Reungwetwattana T, Chewaskulyong B, Lee KH, et al. Osimertinib in untreated EGFR-mutated advanced non-small-cell lung cancer. N Engl J Med. 2018;378:113-25.

21. Kim ES. Olmutinib: first global approval. Drugs. 2016;76:1153-7.

22. Shi YK, Zhang SC, Hu XS, Feng JF, Ma ZY, Zhou JY, et al. Safety, clinical activity and pharmacokinetics of alflutinib (AST2818) in advanced NSCLC patients with EGFR T790M mutation. J Thorac Oncol. 2020; in press.

23. Liu XY, Li W, Zhang YF, Jiang Y, Zhao QY, Zhong DF. Simultaneous determination of alflutinib and its active metabolite in human plasma using liquid chromatography-tandem mass spectrometry. J Pharm Biomed Anal. 2019;176:112735.

24. Rodrigues $A D$. Integrated cytochrome P450 reaction phenotyping. Biochem Pharmacol. 1999;57:465-80.

25. Fahmi OA, Ripp SL. Evaluation of models for predicting drug-drug interactions due to induction. Expert Opin Drug Met. 2010;6:1399-416.

26. Xu Y, Zhou Y, Hayashi M, Shou M, Skiles GL. Simulation of clinical drug-drug interactions from hepatocyte CYP3A4 induction data and its potential utility in trial designs. Drug Metab Dispos. 2011;39:1139-48.

27. Shou M, Hayashi M, Pan Y, Xu Y, Morrissey K, Xu L, et al. Modeling, prediction, and in vitro in vivo correlation of CYP3A4 induction. Drug Metab Dispos. 2008;36:2355-70.

28. Dixit V, Moore A, Tsao H, Hariparsad N. Application of micropatterned cocultured hepatocytes to evaluate the inductive potential and degradation rate of major xenobiotic metabolizing enzymes. Drug Metab Dispos. 2016;44:250-61.

29. Garg V, Chandorkar G, Yang Y, Adda N, McNair L, Alves K, et al. The effect of CYP3A inhibitors and inducers on the pharmacokinetics of telaprevir in healthy volunteers. Br J Clin Pharmacol. 2013;75:431-9.

30. Dickinson PA, Cantarini MV, Collier J, Frewer P, Martin S, Pickup K, et al. Metabolic disposition of osimertinib in rats, dogs, and humans: insights into a drug designed to bind covalently to a cysteine residue of epidermal growth factor receptor. Drug Metab Dispos. 2016:44:1201-12.

31. Vishwanathan K, Dickinson PA, So K, Thomas K, Chen YM, De Castro Carpeno J, et al. The effect of itraconazole and rifampicin on the pharmacokinetics of osimertinib. Br J Clin Pharmacol. 2018;84:1156-69.

32. Tolson $A H$, Wang $H$. Regulation of drug-metabolizing enzymes by xenobiotic receptors: PXR and CAR. Adv Drug Deliv Rev. 2010;62:1238-49. 